\title{
The Sources of Atmospheric Particulate Matter Pollution in a Water Head Site of Beijing in Winter Months
}

\author{
Guo Xinyue $^{1}$. Ji Hongbing ${ }^{1,2, a} \cdot$ Li Cai $^{1} \cdot$ Gao Yang $^{1}$ \\ ${ }^{1}$ Civil and Environmental and Engineering School, University of Science and Technology Beijing, \\ Beijing 100083, China \\ ${ }^{2}$ The State Key Laboratory of Environmental Geochemistry, Institute of Geochemistry, Chinese \\ Academy of Sciences, Guiyang 55002, China \\ ${ }^{a}$ Corresponding Author: ji.hongbing@hotmail.com, Tel \& Fax: 86-10-68909710 (Prof. \& Dr. \\ Hongbing Ji)
}

Keywords: Particulate matter, Trace metal, Sources, Miyun reservoir, Deposition flux, Atmospheric pollution.

Abstract. 11 atmospheric particulate matter sampling sites was created around Miyun reservoir to analyze the mineral composition, element concentration and sources of atmospheric particulate matter pollution by using ICP-MS and XRD analysis. The results show that there are many iron minerals and some unweathered minerals which come from the iron ore yard in the northern mountainous area of Miyun in atmospheric particulate matter. In the eastern and southern of Miyun reservoir, the pollutions of $\mathrm{Cr}, \mathrm{Ni}, \mathrm{Co}$ is clearly, the Annual deposition fluxes of them are respectively $417.04 \mathrm{~g} / \mathrm{hm}^{2} \cdot \mathrm{a} 、 165.90 \mathrm{~g} / \mathrm{hm}^{2} \cdot \mathrm{a} 、 52.19 \mathrm{~g} / \mathrm{hm}^{2} \cdot \mathrm{a}$, which are much higher than the average of Miyun. Comparing with the upwind and downwind in winter months, the element concentration and mineral composition have a great many of differences between the south-eastern and the north-western, which is caused by the Miyun reservoir. The conclusion was that the atmospheric particulate matter pollutions caused by mining activities and anthropogenic influence of is from Surrounding areas and northern mountainous areas, which is useful to control and reduce the pollution of heavy metals in Miyun reservoir.

\section{Introduction}

Particulate matter(PM) has become a public concern ever since the British Clean Air Act was published in $1956^{[1]}$. Atmospheric particulate matter (PM) may be emitted into the atmosphere by a wide variety of sources: natural (i.e., soilerosion, sea spray, volcanic activities) and anthropogenic(i.e., industrial activities, traffic emissions, residential heating,fossil fuel combustion including coal and biomass burning $)^{[2]}$.

Atmospheric deposition is an important mechanism controlling the fate of airborne toxics and their transfer from the atmosphere to the natural surfaces. Atmospheric deposition of particles to ecosystem takes place via both wet and dry processes. Dry deposition of ambient particles is thought to be an important pathway for the introduction of toxic trace elements and heavy metals into theaquatic ecosystem ${ }^{[3]}$.

Trace metals are proven to be useful tracers and are extensively used to identify sources of emissions to be targeted by the emission reduction policies ${ }^{[4,5]}$. Therefore, monitoring of elemental composition of PM has become a crucial part of air quality programs in many countries around the world.

Miyun reservoir locates in the north of Beijing, provides more than 50\% drinking water for people living in Beijing, in which the water influences the health of them. As a part of suspended substance of water, atmospheric particulates pollution proved a major influence of water quality ${ }^{[6]}$, which is also play a role in regional climate change, especially with regard to the water cycle ${ }^{[7]}$. The water-soluble metal, a possible harmful component of airborne PM10, and transition metals such as $\mathrm{Cu}, \mathrm{Fe}$, and $\mathrm{Zn}$, have been hypothesised to cause cellular inflammation ${ }^{[8]}$. The investigation for atmospheric particulates pollution is useful and necessary. 
Although various papers have reported the particulate matter pollution, there is no research in currently combine the mass concentration, mineral composition, morphological characteristics and element concentration to analyze the sources and the transformation processes of the atmospheric particulates. This paper used XRD (X-ray diffraction) analysis and ICP-MS (Inductively coupled plasma mass spectrometry) method to analyze the mineral composition and element concentration of the atmospheric particulates from Miyun reservoir and the northern mountains of Miyun town, and related these data and mass concentration to discuss the sources and the influences of the atmospheric particulates.

\section{Experimental}

\subsection{Description of the sampling sites}

The sampling sites are in the northern mountainous areas in Miyun county town in Beijing of China, which is in a warm temperate zone and has a typical continental monsoon climate with four distinct seasons. In winter, the weather is low temperature and dry, it is often snow and often has northwester. Miyun reservoir undertakes the drinking water and industrial consumption of Beijing, Tianjin and part of Hebei province, which is 188 square kilometers in area and 40-60 meters in depth, the gross storage capacity is 4.375 billion cubic meters. In winter, the highest seasonal average concentrations of PM2.5 and PM10 ${ }^{[9,10]}$, Beijing is cold and dry, the activities of animals and plants are reduce, which is advantaged to observe and analyze.
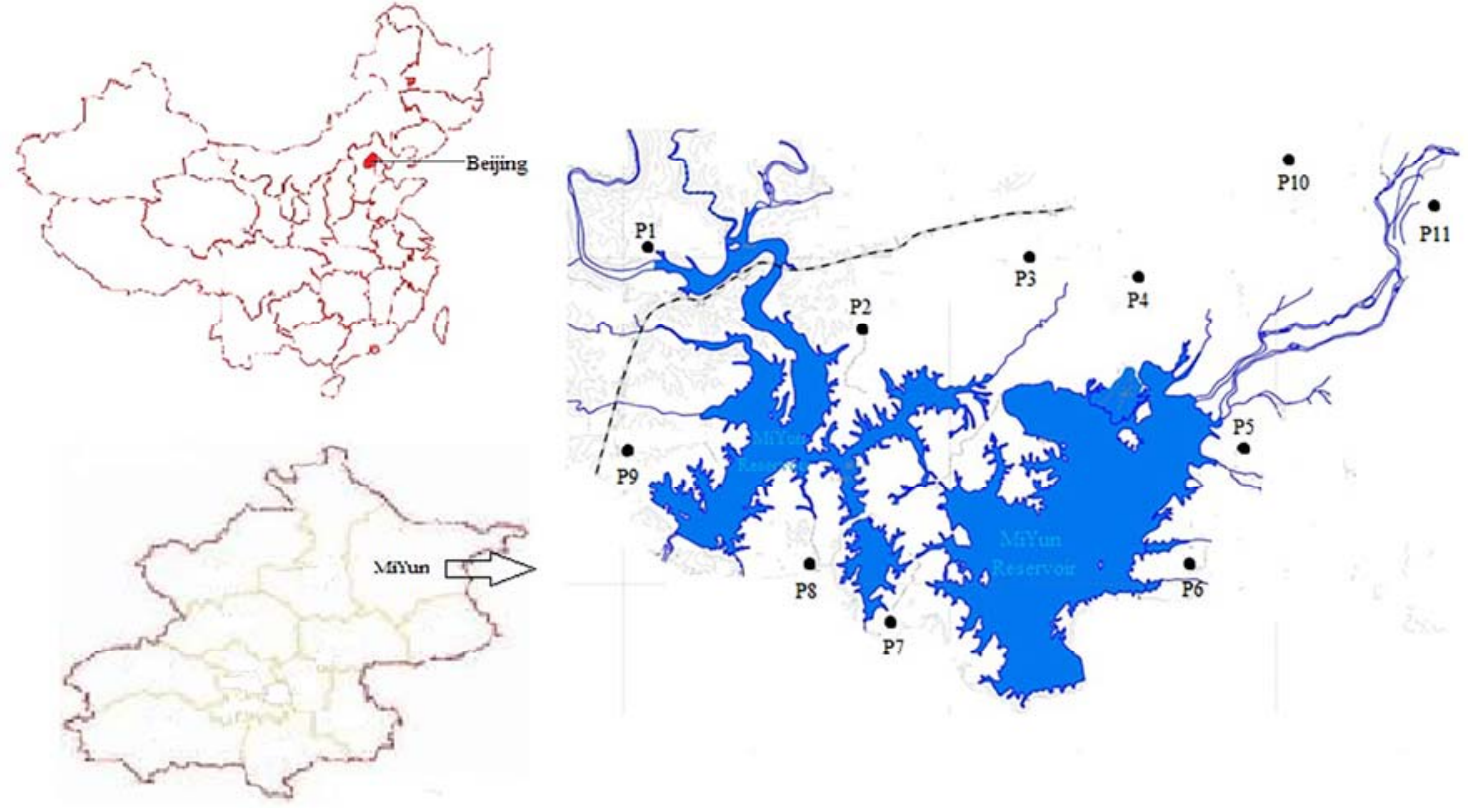

Figure 1 Distribution of sample sites in Miyun reservoir

\subsection{Collection and preliminary treatment of samples}

This research sets 11 sample sites in the upper reaches and surrounding area of Miyun reservoir(Fig 1), 9 sample sites of them are in the surrounding area of the reservoir and the other 2 are in the northern mountains. Monthly sampling of dry deposition was collected by the Dust collection cylinder, which is made of plastic, 30 centimeter in high and 15 centimeter in diameter, setting in 3 meters high off the ground to decrease the local dust. 33 samples were collected continuously for each month from December 2011 to February 2012. 
Table 1 The amount of atmospheric dry deposition form sampling sites

\begin{tabular}{ccccc}
\multicolumn{7}{c}{ Table 1 The amount of atmospheric dry deposition form sampling sites } & (g) \\
\hline No. & Dec & Jan & Feb & 0.23 \\
P1 & 0.24 & 0.30 & 0.16 & 0.20 \\
P2 & 0.19 & 0.21 & $0.20^{*}$ & 0.19 \\
P3 & 0.19 & 0.21 & 0.18 & 0.28 \\
P4 & 0.27 & 0.38 & 0.19 & 0.40 \\
P5 & 0.21 & 0.66 & 0.34 & 0.43 \\
P6 & 0.32 & 0.54 & $0.43^{*}$ & 0.54 \\
P7 & 0.45 & 0.76 & 0.40 & 0.59 \\
P8 & 0.58 & 0.77 & 0.41 & 0.50 \\
P9 & $0.50^{*}$ & 0.56 & 0.43 & 0.41 \\
P10 & 0.47 & 0.78 & 0.28 & 0.51 \\
P11 & 0.26 & 1.07 & 0.20 & $0.40^{* *}$ \\
Ave & 0.33 & 0.57 & 0.29 & \\
\hline
\end{tabular}

*The average of the other two month in that site, because the samples were wetted by rain

**The average of all of the data, the average deposition in winter

\subsection{Sample analysis}

Bulk samples were air dried and then crushed and ground to powder $(<200$ screen mesh $)$ using a mortar and pestle.

The XRD measurement of the samples was carried out on a Rigaku D/Max-2000 X-ray analytical instrumentation with Ni-filtered $\mathrm{CuK} \alpha$ radiation $(35 \mathrm{kV}, 35 \mathrm{~mA})$ and the slit conditions were: $1^{\mathrm{o}}$ divergence slit, $1^{\circ}$ anti-scatter slit, and $0.3 \mathrm{~mm}$ receiving slit. The XRD patterns were collected from 3 to $65^{\circ} 2 \theta$ at a scan rate of $4^{\circ} 2 \theta / \mathrm{min}$.

As shown in literature ${ }^{[11]}, 50 \mathrm{mg}$ samples for ICP-MS which were sealed in Teflon container with 1 $\mathrm{mL} \mathrm{HF}\left(1.15 \mathrm{~g} \mathrm{~mL}^{-1}\right)$ and $0.5 \mathrm{~mL}$ of $\mathrm{HNO}_{3}\left(1.41 \mathrm{~g} \mathrm{~mL}^{-1}\right)$ were acid-digest in an oven at $190^{\circ} \mathrm{C}$ for 24 h. Subsequently, removed the container cover and dried the samples on an electric board at $200^{\circ} \mathrm{C}$, then add $0.5 \mathrm{~mL}$ of $\mathrm{HNO}_{3}$ into the container and dry it again. This process was repeated once. Finally, $5 \mathrm{~mL}$ of $\mathrm{HNO}_{3}\left(8 \mathrm{~mol} \mathrm{~L}^{-1}\right)$ was added and the solution was transferred to clean $50 \mathrm{~mL}$ volumetric flasks and diluted to $50 \mathrm{~mL}$ using Milli-Q water (resistance $=18.2 \mathrm{MXcm}^{-1}$ ). The solution was ready for element concentrations analysis.

Trace metal concentrations were analyzed by using inductively coupled plasma mass spectrometry (ICP-MS, ELAN DRC-e, PerkinElmer) equipped with a laser ablation sample introduction system(LA-ICP-MS, GeoLasPro 193nm, Coherent). Twelve kinds of metals were measured in every atmospheric particulates sample by monitoring the following ions: $\mathrm{Cr}, \mathrm{Co}, \mathrm{Ni}, \mathrm{Cu}, \mathrm{Zn}, \mathrm{Ga}, \mathrm{Ge}, \mathrm{As}$, $\mathrm{Mo}, \mathrm{Ag}, \mathrm{Cd}, \mathrm{Pb}$. Details of the LA/ICP-MS method have been described by several papers ${ }^{[12]}$.

\section{3. results and discussion}

\subsection{Mineral composition analysis}

The XRD results showed that the atmospheric particulates in that place are mainly quartz, plagioclase, calcite, ledikite, kaolinite and turface, which are similar with soil. Gypsum, a peculiar mineral in northern arid area, was found in some of the samples. Most of the samples included calcite, which is a low weathered mineral showed that the source of the samples are near to the sample sites. Iron minerals were found in all the samples and the sample of P11 had the highest concentration. Considered the sources of calcite, these iron minerals may came from the iron ore yard in surrounding areas and transferred to the sample sites by monsoon. 


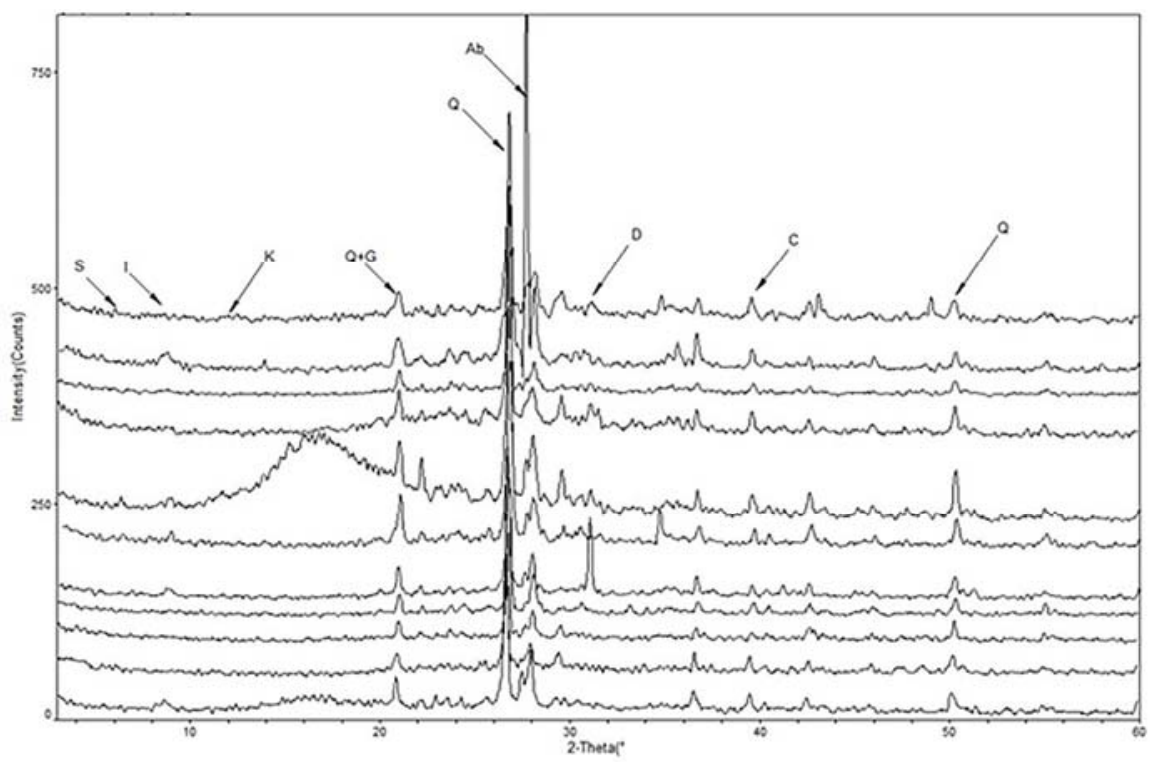

Figure 2 XRD analysis results

In P5 sample, there are high concentration of dolomites, and in P7, P8, P9, P10 samples, a little of dolomites were found. In P6, P11 samples, hornblendes were surveyed. The peaks of calcite were very clear in P2, P3, P7, P8 samples. In P7 sample, there is an unusual peak, which shows a plenty of noncrystalline minerals in the sample. There are many iron minerals in P11 sample, which caused by a working iron ore yard near by the sample site.

Comparing with the XRD analysis results of the adjacent samples sites in figure 2, it is found that the mineral composition of P2, P3, P4 samples are similar, and the mineral composition of P8, P9 and the latter half of P7 samples are similar too, and the nearer of the sample sites the more similar the mineral composition they have, which showed that the sources of the adjacent sample sites are same. In contrast, the result of the sample sites far from each other are different, especially the sites of southeast and northwest, and the mineral composition of them have a huge differences.

\subsection{Trace element concentration}

Using Plasma mass spectrometry (ELAN DRC-e, PerkinElmer) and LA-ICP-MS (GeoLasPro 193nm, Coherent), analyzed the element concentration of atmospheric particulates. The analysis results were collected in table 2 .

Table 2 Concentration of trace element of atmospheric particulates in winter ( $\mathrm{ppm})$

\begin{tabular}{ccccccccccccc}
\hline \multirow{2}{*}{ Element } & & \multicolumn{1}{c}{ Sample } & \multicolumn{1}{c}{ P9 } & P10 & P11 \\
\hline $\mathrm{Cr}$ & 79.31 & 59.40 & 66.63 & 99.05 & 68.88 & 115.02 & 82.60 & 69.70 & 91.63 & 104.07 & 120.36 \\
$\mathrm{Co}$ & 11.78 & 11.36 & 10.32 & 13.02 & 10.82 & 11.10 & 12.59 & 13.02 & 13.90 & 14.62 & 14.39 \\
$\mathrm{Ni}$ & 37.96 & 81.57 & 43.02 & 40.43 & 30.19 & 31.86 & 34.05 & 39.29 & 51.30 & 45.33 & 47.88 \\
$\mathrm{Cu}$ & 43.15 & 59.73 & 115.59 & 53.71 & 34.57 & 103.75 & 40.26 & 40.90 & 105.21 & 33.59 & 63.10 \\
$\mathrm{Zn}$ & 455.71 & 607.85 & 344.64 & 400.63 & 690.37 & 310.00 & 238.13 & 513.16 & 472.11 & 284.15 & 668.82 \\
$\mathrm{Ga}$ & 13.39 & 11.10 & 12.54 & 13.51 & 12.83 & 12.61 & 12.04 & 12.44 & 13.30 & 12.91 & 12.97 \\
$\mathrm{Ge}$ & 1.23 & 1.17 & 1.05 & 1.19 & 1.05 & 1.15 & 1.29 & 2.26 & 1.08 & 1.06 & 1.27 \\
$\mathrm{As}$ & 8.90 & 8.56 & 9.06 & 8.81 & 9.18 & 9.39 & 8.41 & 9.22 & 9.15 & 8.78 & 9.05 \\
$\mathrm{Mo}$ & 1.70 & 3.48 & 1.90 & 1.12 & 1.12 & 1.53 & 1.70 & 2.07 & 1.67 & 2.75 & 2.28 \\
$\mathrm{Ag}$ & 0.51 & 0.63 & 0.71 & 0.67 & 0.55 & 0.47 & 0.59 & 0.77 & 0.51 & 0.34 & 0.49 \\
$\mathrm{Cd}$ & 2.02 & 1.04 & 0.82 & 0.72 & 0.66 & 0.66 & 0.88 & 2.48 & 1.31 & 0.49 & 0.99 \\
$\mathrm{~Pb}$ & 44.79 & 72.50 & 70.46 & 60.05 & 83.32 & 49.72 & 68.87 & 159.38 & 69.97 & 47.68 & 69.75 \\
\hline
\end{tabular}


Comparing each of the element concentration singly, we found that some elements like As, $\mathrm{Ag}, \mathrm{Ga}$ the concentrations of them were steady in all the sample sites of the area without any regional difference, which showed these element sedimentations in Miyun reservoir area were average(Fig 3).

$\mathrm{Ni}, \mathrm{Cu}, \mathrm{Ge}, \mathrm{Pb}$ element concentrations were similar in a majority of places, but one or several sites had unusual high peaks(Fig 3), these peaks may caused by human beings and animal movements.

$\mathrm{Cr}$ element concentration in P6, P10, P11 sample sites are higher than in other sites, the concentrations are more than 100ppm, and P4 sample has a high concentration of $\mathrm{Cr}$, too. These sample sites are distribution in the east and the north of Miyun reservoir, which showed that the pollution of $\mathrm{Cr}$ is a regional pollution, the source of $\mathrm{Cr}$ is the neighboring area. In P9, P10, P11 sample sites, Co is higher than other sites, and in P2, P10, P11 Mo is higher than others. Form the three elements above, we found that these elements in P10 and P11 sites have the higher concentrations than others, this may because of the activity of iron ore yard in the surrounding area(Fig 3).

Cd element concentration in P8 sample site is the highest one, and in P1, P2, P9 are also higher, but the concentrations in P5, P6, P10 is lower than other. Generally speaking, Cd distribution is higher in southeast and lower in northwest, makes a obvious different form southeast to northwest, which is similar to the results of XRD.

The distribution of $\mathrm{Zn}$ is irregular, and the highest element concentration in P5 reach the $690.37 \mathrm{ppm}$, the lowest in $\mathrm{P} 7$ is $238.13 \mathrm{ppm}$.
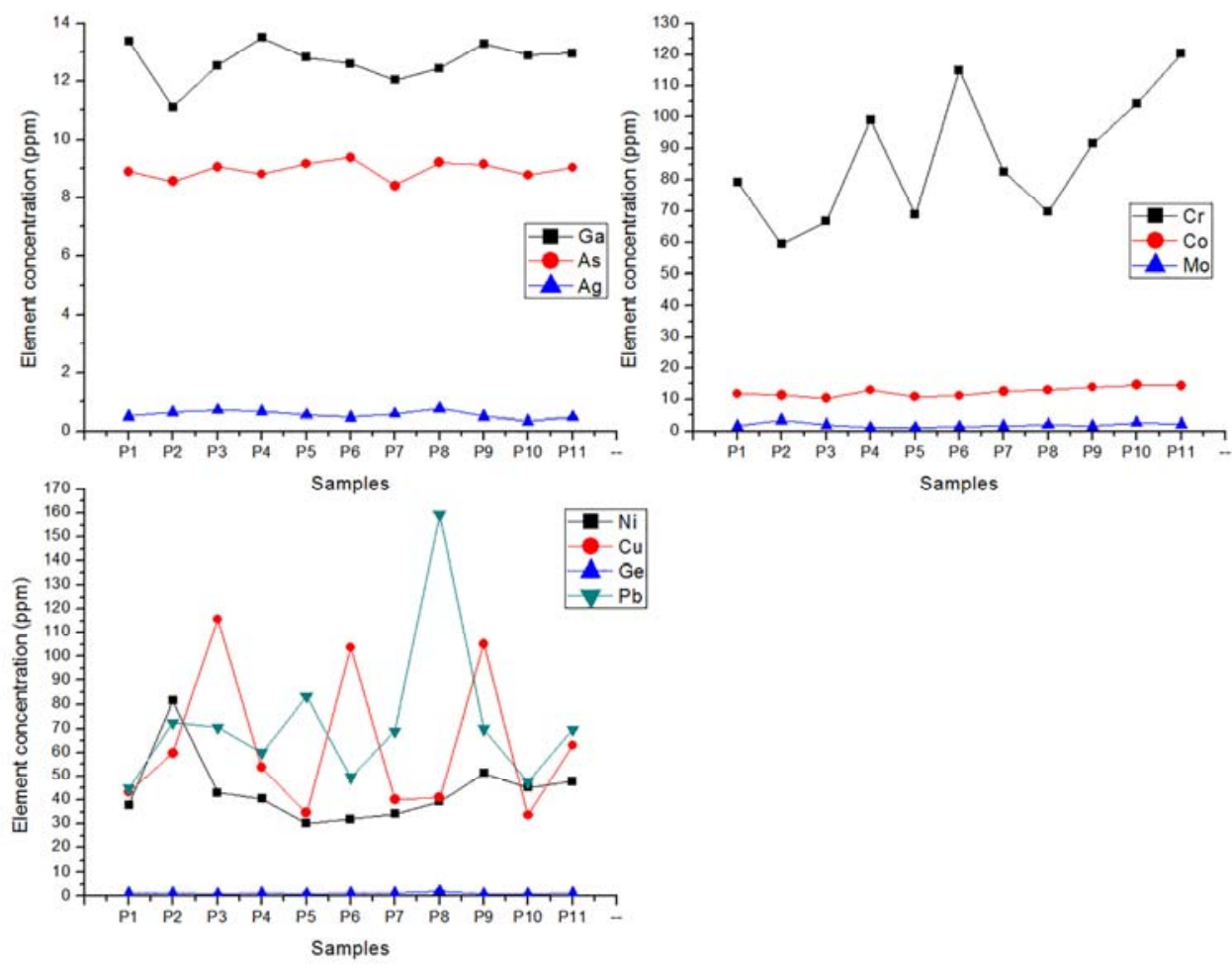

Figure 3 Element concentrations of heavy metals

Compared with the soil quality standards (GB15618-1995), the element concentration of heavy metals (Table 2) in the area were higher, some places have heavy metal pollutions. The concentrations of $\mathrm{Zn}$ were higher than the concentration of class II, and the concentrations in P2, P5, P8, P11 samples were higher than 500ppm, the excessive concentrations of $\mathrm{Zn}$ were harm for human's healthy, the Zn pollution in this areas was serious. The highest concentration of Cd element was $2.48 \mathrm{ppm}$, which was much higher than the level of classIII, which was only $1.0 \mathrm{ppm}$, and there were other 3 samples were higher than the standard III, all of the samples were higher than standard 
II, the pollution of $\mathrm{Cd}$ in the reservoir area were serious, too. The element concentration of $\mathrm{Cu}$ were higher than standard of class I, the P3, P6, P9 samples were a little higher than class II, the pollution of $\mathrm{Cu}$ was moderate. The concentration of $\mathrm{Cr}, \mathrm{Pb}, \mathrm{Ni}$ were mainly in the class $\mathrm{II}$, some of the samples were in class I, and none of them was higher than the standard of class II, the pollutions of these element were not serious. The concentration of As were low, all of the samples were in class I, there was nothing As pollution in this areas.

\subsection{Regularity of element deposition flux}

According to the results of ICP-MS analysis, count the deposition flux of element by the formula below.

$$
\mathrm{Q}=10000 \times \mathrm{M} / \mathrm{S}=\mathrm{W} \times \mathrm{C} / 100 \times \mathrm{S}
$$

In the formula, $\mathrm{Q}$ means deposition flux of element per month $\left(\mathrm{g} /\left(\mathrm{hm}^{2} \cdot \mathrm{month}\right)\right), \mathrm{M}$ means the deposition weight of element per month ( $\mathrm{g} /$ month $)$, S means the sguare measure of dust collection cylinder $\left(\mathrm{m}^{2}\right), \mathrm{W}$ means the settling amount of deposition per month $(\mathrm{g}), \mathrm{C}$ means the element concentration ( $\mathrm{ppm}$ ).

The sguare measure of dust collection cylinder $\left(\mathrm{m}^{2}\right)$ counted

$$
\mathrm{S}=\times \mathrm{d}^{2} / 40000
$$

In the formula, $\mathrm{S}$ means the sguare measure of dust collection cylinder $\left(\mathrm{m}^{2}\right), \mathrm{d}$ means the diameter of the dust collection cylinder $(\mathrm{cm})$.

The results of the deposition flux of element are listed in table 3.In table 3, Deposition flux of $\mathrm{Zn}$ element is the highest one, reaches $193.12 \mathrm{~g} /\left(\mathrm{hm}^{2} \cdot\right.$ month $)$, the next are $\mathrm{Cr}>\mathrm{Cu}>\mathrm{Pb}>\mathrm{Ni}$, and trace elements like $\mathrm{Ge}, \mathrm{Mo}, \mathrm{Ag}, \mathrm{Cd}$ are low. Comparing with the element deposition flux of P1-P9 sample sites (Fig 4), we found that the deposition flux of element in the northwest sample sites, P1-P5, is lower than that in the southeast, P6-P9. The reason of this difference is that the northwester monsoon in Beijing in winter is influenced by the Miyun reservoir, so the element deposition flux in the two side of reservoir is different.

\begin{tabular}{|c|c|c|c|c|c|c|c|c|c|c|c|}
\hline \multirow{2}{*}{ Element } & \multicolumn{11}{|c|}{ Sample } \\
\hline & $\mathrm{P} 1$ & $\mathrm{P} 2$ & $\mathrm{P} 3$ & $\mathrm{P} 4$ & P5 & P6 & $\mathrm{P} 7$ & P8 & P9 & $\mathrm{P} 10$ & $\mathrm{P} 11$ \\
\hline $\mathrm{Cr}$ & 10.33 & 6.73 & 7.17 & 15.70 & 15.60 & 28.00 & 25.25 & 23.28 & 25.94 & 24.16 & 34.75 \\
\hline Co & 1.53 & 1.29 & 1.11 & 2.06 & 2.45 & 2.70 & 3.85 & 4.35 & 3.93 & 3.39 & 4.16 \\
\hline $\mathrm{Ni}$ & 4.94 & 9.24 & 4.63 & 6.41 & 6.84 & 7.76 & 10.41 & 13.12 & 14.52 & 10.52 & 13.83 \\
\hline $\mathrm{Cu}$ & 5.62 & 6.76 & 12.43 & 8.51 & 7.83 & 25.26 & 12.31 & 13.66 & 29.78 & 7.80 & 18.22 \\
\hline $\mathrm{Zn}$ & 59.34 & 68.83 & 37.07 & 63.51 & 156.35 & 75.47 & 72.80 & 171.42 & 133.65 & 65.96 & 193.12 \\
\hline $\mathrm{Ga}$ & 1.74 & 1.26 & 1.35 & 2.14 & 2.91 & 3.07 & 3.68 & 4.16 & 3.77 & 3.00 & 3.75 \\
\hline $\mathrm{Ge}$ & 0.16 & 0.13 & 0.11 & 0.19 & 0.24 & 0.28 & 0.39 & 0.75 & 0.31 & 0.25 & 0.37 \\
\hline As & 1.16 & 0.97 & 0.97 & 1.40 & 2.08 & 2.29 & 2.57 & 3.08 & 2.59 & 2.04 & 2.61 \\
\hline Mo & 0.22 & 0.39 & 0.20 & 0.18 & 0.25 & 0.37 & 0.52 & 0.69 & 0.47 & 0.64 & 0.66 \\
\hline $\mathrm{Ag}$ & 0.07 & 0.07 & 0.08 & 0.11 & 0.12 & 0.11 & 0.18 & 0.26 & 0.14 & 0.08 & 0.14 \\
\hline $\mathrm{Cd}$ & 0.26 & 0.12 & 0.09 & 0.11 & 0.15 & 0.16 & 0.27 & 0.83 & 0.37 & 0.11 & 0.29 \\
\hline $\mathrm{Pb}$ & 5.83 & 8.21 & 7.58 & 9.52 & 18.87 & 12.10 & 21.06 & 53.24 & 19.81 & 11.07 & 20.14 \\
\hline
\end{tabular}

Table 3 Deposition flux of trace element in Miyun reservoir $\left(\mathrm{g} /\left(\mathrm{hm}^{2} \cdot \mathrm{month}\right)\right)$

In table 3, the concentrations of two heavy metals $\mathrm{Cr}$ and $\mathrm{Ni}$ are higher than the average concentration in Miyun town. This result may caused by the frequent activities of exploiting iron mine because the elements $\mathrm{Cr}$ and $\mathrm{Ni}$ are the associated ores of iron mine, which shows that the activities of iron mine can make serious heavy metal pollutions. Meanwhile, the samples for this research were collected in winter, the highest season of concentration of atmospheric particulates ${ }^{[9,10]}$, and therefore the annual element deposition flux counted by these samples increased. 
The annual element deposition flux of As and Mo are equal to the average of Miyun town, showed that the two elements depositing in Miyun town is a steady process. And combine with the element concentrations of these, it found that the elements As and Mo are not influenced by the activities of iron mine.

The average element deposition flux of Cd are higher than it of Miyun town, but the deposition flux of single site is near to the average of Miyun town, except the sites near to P8 sample site. In P8 sample, there is a very high concentration of Cd element, and in $\mathrm{P} 7$ and $\mathrm{P} 9$, the concentration is higher than other sites, which showed the pollution of $\mathrm{Cd}$ element is a regionality pollution and the sources of the $\mathrm{Cd}$ are near by the P8 sample site.

$\mathrm{Pb}$ element is one of the automobile exhaust pollution indicators. The distribution of $\mathrm{Pb}$ in table 3 is similar with $\mathrm{Cd}$, the element deposition flux of most sample sites are equal or even less than the average of Miyun town, but near the P8 sample site there are some higher concentrations, which are similar with these data of metropolis with frequent automotive activities. And therefore there is a conclusion that in P8 place there are a lot of automobile exhausting and human activities, which are the reasons of both of $\mathrm{Pb}$ pollution and $\mathrm{Cd}$ pollution.
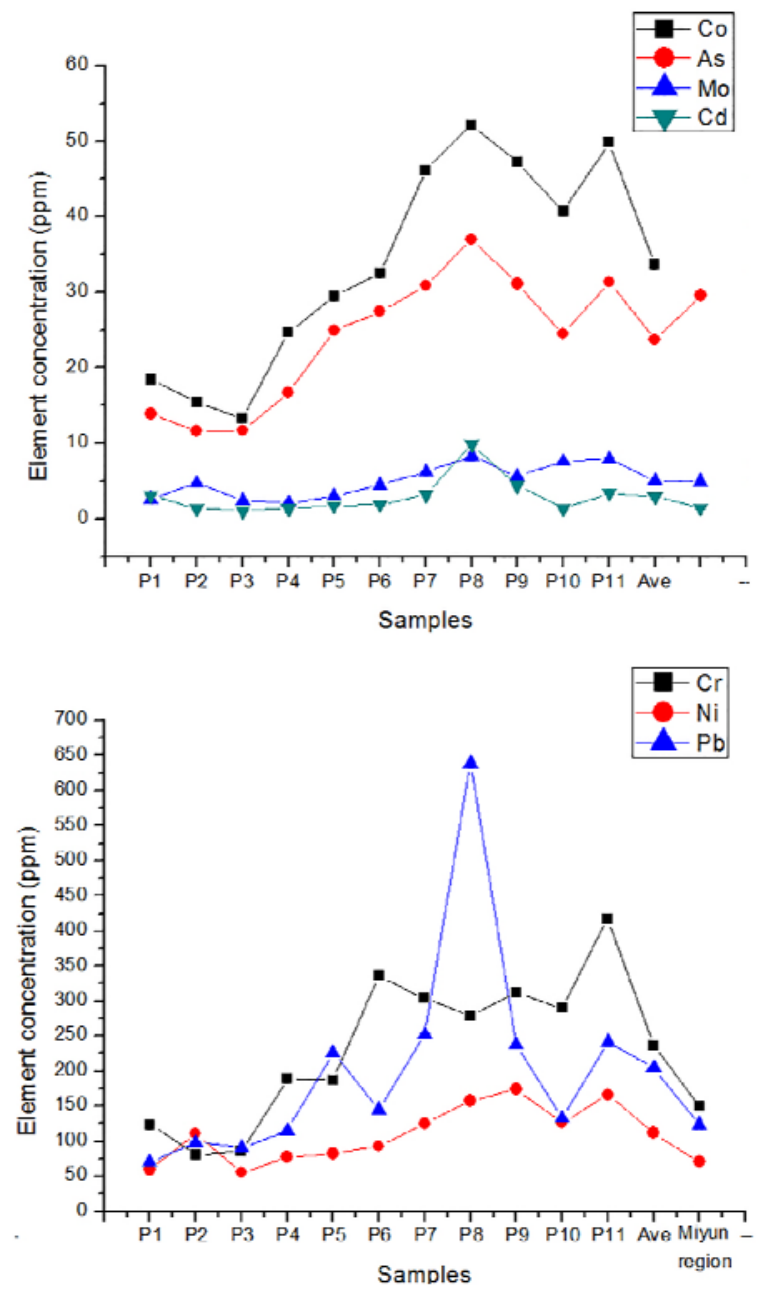

Figure 4 The Deposition fluxes of heavy metals $\mathrm{Cr}, \mathrm{Ni}, \mathrm{Pb}$ and $\mathrm{Co}$, As, Mo, Cd in different places

\subsection{Statistics analysis}

Correlation analysis. According to the element concentration results in table 2, analyze the correlation of heavy metals in atmospheric particulates by SPSS software. In table 5, the correlation coefficient of $\mathrm{Cr}$, Co and $\mathrm{Ga}$ are high, $\mathrm{Ni}$, Mo have a high positive correlation, the deposition of Ge, $\mathrm{Ag}, \mathrm{Cd}$, and $\mathrm{Pb}$ are similar with each other.

The correlation coefficient of $\mathrm{Ni}$, Mo is 0.821 , explaining that these two elements may come from same place. In consideration of that both of them are associated minerals of iron mines, the source of 
them are the iron mines of Miyun town. $\mathrm{Zn}$ has a positive correlation to Ni and Mo, but the correlation coefficient is not very high, shows that part of the $\mathrm{Zn}$ element come from iron mines.

$\mathrm{Cr}$ and $\mathrm{Co}$ are the heavy metal pollution of iron mines, too. The correlation coefficient of them is 0.575 , shows that they are also from iron mines. However, the coefficients of $\mathrm{Cr}$ and $\mathrm{Co}$ to $\mathrm{Ni}$ and Mo are negative, the reason of this, I think, is they all come from iron mines, but the iron mine of $\mathrm{Cr}, \mathrm{Co}$ is not the same one of $\mathrm{Ni}$, Mo. Because in element concentration analysis (Table 2), the highest concentration sample sites of $\mathrm{Cr}$ and $\mathrm{Co}$ are P6, P10 and P11, but the highest one of Ni, Mo is P2.

The highest correlation coefficient in this analysis is $\mathrm{Pb}$ to $\mathrm{Ge}$, reaches 0.878 . The deposition of $\mathrm{Pb}$ is greatly influenced by human beings, especially automobile exhaust pollution. Thus, the pollution of these elements, $\mathrm{Pb}, \mathrm{Ge}, \mathrm{Cd}$ and $\mathrm{Ag}$, are probably caused by human activities, the sources of them may be adjacent areas.

Principal component analysis. Using the SPSS software, analyze the principal component of atmospheric particulates. The orthogonal rotation results show that four principal components can explain $79.79 \%$ of the variance, and the distribution of the first principal component is $26.54 \%$ (Table 6). The first component correlates well with $\mathrm{Pb}, \mathrm{Ge}$, and $\mathrm{Cd}$, and it is attributed to cars using gasoline and diesel fuels because $\mathrm{Pb}$ is one of the indicator elements of gasoline and diesel fuels using ${ }^{[13]}$. In the second component correlate, $\mathrm{Ni}$ and Mo have high positive distributions, 0.950 and 0.918, respectively. $\mathrm{Ni}$ and Mo are accompanying minerals of iron mines, and the sources of them are adjacent areas. The third principal component highly correlates with $\mathrm{Cr}$, $\mathrm{Co}$ and $\mathrm{Ga}$ which are also from iron mine yards. However, the iron mine yards of $\mathrm{Cr}$, $\mathrm{Co}$ and $\mathrm{Ga}$ are not the same ones as them of $\mathrm{Ni}$ and Mo. The fourth principal component correlates well with $\mathrm{Cu}$ and As. The burdening of them are 0.742 and 0.827 , respectively.

Table 5 Correlation analysis of heavy metals in atmospheric particulates

\begin{tabular}{|c|c|c|c|c|c|c|c|c|c|c|c|c|}
\hline & $\mathrm{Cr}$ & $\mathrm{Co}$ & $\mathrm{Ni}$ & $\mathrm{Cu}$ & $\mathrm{Zn}$ & $\mathrm{Ga}$ & $\mathrm{Ge}$ & As & Mo & $\mathrm{Ag}$ & $\mathrm{Cd}$ & $\mathrm{Pb}$ \\
\hline$\overline{\mathrm{Cr}}$ & 1 & 0.064 & 0.417 & 0.677 & 0.535 & 0.123 & 0.547 & 0.483 & 0.629 & 0.041 & 0.291 & 0.191 \\
\hline Co & 0.575 & 1 & 0.791 & 0.403 & 0.920 & 0.285 & 0.598 & 0.673 & 0.557 & 0.225 & 0.833 & 0.924 \\
\hline $\mathrm{Ni}$ & -0.273 & 0.091 & 1 & 0.747 & 0.326 & 0.074 & 0.761 & 0.222 & 0.002 & 0.811 & 0.968 & 0.950 \\
\hline $\mathrm{Cu}$ & 0.142 & -0.281 & 0.110 & 1 & 0.577 & 0.910 & 0.357 & 0.168 & 0.776 & 0.799 & 0.605 & 0.560 \\
\hline $\mathrm{Zn}$ & -0.210 & -0.035 & 0.327 & -0.189 & 1 & 0.855 & 0.724 & 0.466 & 0.705 & 0.684 & 0.507 & 0.315 \\
\hline $\mathrm{Ga}$ & 0.493 & 0.354 & -0.559 & 0.039 & -0.063 & 1 & 0.669 & 0.203 & 0.029 & 0.389 & 0.888 & 0.463 \\
\hline $\mathrm{Ge}$ & -0.204 & 0.179 & -0.104 & -0.308 & 0.121 & -0.146 & 1 & 0.604 & 0.842 & 0.081 & 0.005 & 0.000 \\
\hline As & 0.237 & -0.144 & -0.401 & 0.447 & 0.246 & 0.416 & 0.176 & 1 & 0.214 & 0.967 & 0.595 & 0.436 \\
\hline Mo & -0.165 & 0.199 & $0.821^{* *}$ & -0.097 & 0.129 & $-0.654^{*}$ & 0.068 & -0.407 & 1 & .733 & 0.895 & 0.902 \\
\hline $\mathrm{Ag}$ & $-0.622^{*}$ & -0.399 & 0.082 & 0.087 & 0.139 & -0.289 & 0.548 & -0.014 & -0.116 & 1 & 0.190 & 0.025 \\
\hline $\mathrm{Cd}$ & -0.350 & 0.072 & 0.014 & -0.176 & 0.224 & 0.048 & $0.777^{* *}$ & 0.181 & 0.045 & 0.427 & 1 & 0.040 \\
\hline $\mathrm{Pb}$ & -0.427 & 0.033 & -.0021 & -0.198 & 0.334 & -0.247 & $0.878^{* *}$ & 0.262 & 0.042 & $0.668^{*}$ & $0.623^{*}$ & 1 \\
\hline
\end{tabular}

The left lower part was correlation coefficient, and the right upper part was significant level. $\mathrm{N}=11$, $* \mathrm{P}<0.05 ; * * \mathrm{P}<0.01$.

Cluster analysis. Cluster analysis divides the trace elements into four groups, and this result is similar with the results of correlation analysis and principal component analysis. In figure $5, \mathrm{~Pb}, \mathrm{Ge}$ and $\mathrm{Cd}$ are one cluster, $\mathrm{Ni}$ and $\mathrm{Mo}$ are another, $\mathrm{Cu}$ and $\mathrm{As}$ are another too, and $\mathrm{Cr}, \mathrm{Co}$ and $\mathrm{Ga}$ are the last group. The result of cluster analysis supports the conclusions of correlation analysis and principal component analysis, the main origin of heavy metals are iron mine activities and motor vehicles. 
Table 6 Rotated component matrix of principal component analysis

\begin{tabular}{|c|c|c|c|c|c|}
\hline & \multicolumn{4}{|c|}{ component } & \multirow{2}{*}{ Communality } \\
\hline & 1 & 2 & 3 & 4 & \\
\hline $\mathrm{Cr}$ & -0.310 & -0.237 & 0.795 & 0.159 & 0.809 \\
\hline $\mathrm{Co}$ & 0.180 & 0.116 & 0.874 & -0.242 & 0.869 \\
\hline $\mathrm{Ni}$ & -0.047 & 0.950 & -0.059 & 0.035 & 0.910 \\
\hline $\mathrm{Cu}$ & -0.335 & 0.004 & -0.204 & 0.742 & 0.705 \\
\hline $\mathrm{Zn}$ & 0.390 & 0.385 & 0.060 & 0.394 & 0.459 \\
\hline $\mathrm{Ga}$ & -0.034 & -0.669 & 0.528 & 0.221 & 0.777 \\
\hline $\mathrm{Ge}$ & 0.938 & -0.040 & -0.019 & -0.126 & 0.898 \\
\hline As & 0.250 & -0.371 & 0.127 & 0.827 & 0.901 \\
\hline Mo & 0.019 & 0.918 & 0.082 & -0.179 & 0.883 \\
\hline $\mathrm{Ag}$ & 0.558 & -0.019 & -0.682 & 0.033 & 0.779 \\
\hline $\mathrm{Cd}$ & 0.836 & -0.002 & -0.038 & 0.017 & 0.701 \\
\hline $\mathrm{Pb}$ & 0.914 & 0.048 & -0.211 & 0.051 & 0.884 \\
\hline Percentage of variance & 26.54 & 21.29 & 18.82 & 13.13 & \\
\hline Percentage of cumulative variance & 26.54 & 47.83 & 66.66 & 79.79 & \\
\hline
\end{tabular}

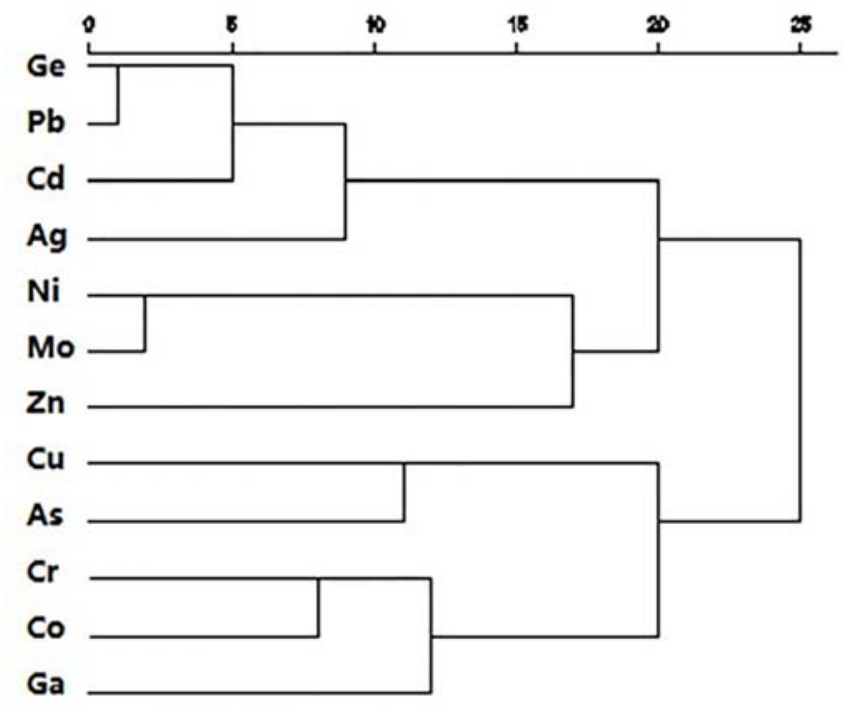

Figure 5 Dendrogram of hierarchical cluster analysis

\subsection{Geographical Differences and Reservoir effect}

Comparing the mineral composition and element concentration of southeast to northwest of Miyun reservoir, it was found a interesting fact: the results of southeast and northwest were considerably different.

In XRD analysis, the atmospheric particulates of Miyun reservoir drainage area in Beijing in winter has a obvious characteristic of arid regions in north of China, the main minerals are quartz, plagioclase, ledikite and kaolinite, contained some gypsum and calcite. Influent by monsoon weather and reservoir, the atmospheric particulates of southeast and northwest are different. In all of the samples, iron minerals were found and the sources of these iron minerals were iron ore yards in the north of reservoir.

Water environment is proved can influent the atmosphere climate ${ }^{[14,15]}$. The chips which are caused by exploitation, transportation and treatment of iron minerals move to the reservoir areas by monsoon. They are wetted by the damp atmosphere above on the reservoir, turn to heavier and then drop into the reservoir when they were crossing the Miyun reservoir. Thus, these particulate matters 
do not arrive in southeast of the reservoir, caused the sources of the two side of Miyun reservoir different.

\section{Conclusion}

1.The mineral composition analysis and morphological characteristics analysis show that the major minerals in the atmospheric particulates of Miyun reservoir area are quartz, plagioclase, ledikite, calcite, dolomite, gypsum and clay minerals, and there are a number of iron minerals in the atmospheric particulate matter.

2.Because of the frequent activities of iron mines in the north of Miyun town, there are some heavy metal pollutions in reservoir areas. $\mathrm{Cr}, \mathrm{Ni}$, Co element pollutions are more serious, the annual element deposition flux are $417.04 \mathrm{~g} / \mathrm{hm}^{2} \cdot \mathrm{a} 、 165.90 \mathrm{~g} / \mathrm{hm}^{2} \cdot \mathrm{a} 、 52.19 \mathrm{~g} / \mathrm{hm}^{2} \cdot \mathrm{a}$, respectively, which are much higher than the average of Miyun town. The elements $\mathrm{Pb}$ and $\mathrm{Cd}$ are influenced by human activities, which cause some regional pollution near by the P8 sample site. The fluxes of As, Co element are near to the average with no metal pollution.

3.The sources of atmospheric particulate matter are mixture, both neighboring and faraway. Coal combustion, vehicle exhaust and mining are the main emission factors in the Miyun reservoir areas. Common minerals like quartz, gypsum and clay minerals are mostly nature deposition, and pollution minerals are usually caused by human activities. The sources of trace elements like Ni, Mo, $\mathrm{Zn}, \mathrm{Cr}$ and $\mathrm{Co}$ are iron mines near by the sample sites. $\mathrm{Pb}, \mathrm{Ge}$ and $\mathrm{Cd}$ are from vehicle exhaust. As and $\mathrm{Cu}$ are from coal combustion.

4.In the southeast and the northwest of Miyun reservoir, the element concentration and mineral composition of atmospheric particulates obviously have many differences. The reason is when the northwester monsoon in winter is crossing the Miyun reservoir, it is wetted by the air on the reservoir, the atmosphere particulates of it is turned to be heavier, and then drop into the reservoir, which causes the sources of the atmospheric particulates in the southeast and northwest different.

\section{References}

[1] N..A. Saliba, R. Massoud. Environ. Sci. and Engine., Urban Airborne Particulate Matter, (2011), 3-17

[2] K. Melik, D. Yetkin, A. Hasan, E. Tolga, O. Mustafa, B. Abdurrahman. Atmos. Res. 149, (2014), 204-216

[3] H.J. Yun, S.M. Yi, Y.P. Kim. Atmos. Environ. 36. (2002). 5449-5458

[4] X. Querol, M. Viana, A. Alastuey, F. Amato, T. Moreno, S. Castillo, J. Pey, J. Rosa, A.S. Campa, B. Artinano, P. Salvador, S.G.D Santos, P.R. Fernandez, G.S. Moreno, L. Negral, M.C. Minguillon, E. Monfort, J.I. Gil, A. Inza, L.A. Ortega, J.M. Santamaria, J. Zabalza. Atmos. Environ., (2007), 24.

[5] X. Querol, X. Zhuang, A. Alastuey, M. Viana, W. Lv, Y. Wang, A. Lopez, Z. Zhu, H. Wei, S. Xu. J. Environ. Monit. 8, (2006)1049-1059

[6] G.J. Keeler, N. Pirrone. Water Sci. Technol., 33: (1996), 259-265

[7] M.O. Andreae. Philosophical Transactions of the Royal Society 365: (2007) 1915-1923

[8] K. Donaldson, D.M. Brown, C. Mitchell, M. Dineva, P.H. Beswick, P. Gilmour, W. MacNee. Environ. Health Persp, 105, (1997), 1285-1290.

[9] K. He, F. Yang, Y. Ma, Q. Zhang, X.H. Yao, C.K. Chan, S.H. Cadle, T. Chan, P.A. Mulawa. Atmos. Environ. 35, (2001), 4959-4970

[10] F.K. Duan, K. He, Y.L. Ma, F.M. Yang, X.C. Yu, S.H. Cadle, T. Chan, P.A. Mulawa. Sci. Total. Environ. 355, (2006), 264-275 
[11] H.J. Ding, H.B. Ji. Environ. Earth Sci. 61, (2010), 641-657

[12] S.Y. Tanaka, N. Narita, T. Sato, S.J. Fukasawa, K. Santosa, T. Yamanaka, Ootoshi. J. Anal. Atm. Spectrom. 13, (1998), 135-140

[13] G.R. Cass, G.J. McRae. Environ. Sci. Technol. 17, (1983), 129-139

[14] K.A. Anderson, J.A. Downing. Water Air Soil Pollut. 176, (2006), 351-374.

[15] S. Hsu, G. Wong, G. Gong. Mar. Chem. 120, (2010), 116-127 